Article

\title{
Modeling Obstruction and Restoration of Urban Commutation Networks in the Wake of a Devastating Earthquake in Tokyo
}

\section{Toshihiro Osaragi}

Department of Mechanical and Environmental Informatics, Graduate School of Information Science and Engineering, Tokyo Institute of Technology, 2-12-1-W8-10 O-okayama, Meguro-ku, Tokyo 152-8552, Japan; E-Mail: osaragi.t.aa@m.titech.ac.jp; Tel.: +81-3-5734-3162; Fax: +81-3-5734-2817

Academic Editors: Christoph Aubrecht and Wolfgang Kainz

Received: 13 April 2015 / Accepted: 13 June 2015 / Published: 7 July 2015

\begin{abstract}
In the aftermath of a devastating earthquake, public transportation is presumed paralyzed and thus unavailable; large numbers of people are expected to experience difficulty in commuting. In recent years, implementation of district continuity plans (DCPs) and business continuity plans (BCPs) has become a major concern for local governments and private firms, respectively. In this paper, we propose a pair of simulation models seeking to examine business commutation networks in terms of their possible obstruction and eventual restoration. The first of these model commuting intentions by analyzing individual daily commutes. The second offers a mobility model of commuters' physical endurance for travel alternatives on foot or by bicycle. Next, we proceed to gauge the number of commuters likely to experience difficulty and adjudge their spatial distribution while taking into account such attributes as gender and employment. Lastly, we attempt to assess rates and patterns in the reduction of commutation constraints based on simulations that assume a restoration of rail infrastructure or its equivalent.
\end{abstract}

Keywords: devastating earthquake; intention to commute; travel alternatives; difficulty in commuting

\section{Introduction}

Reports on the 1994 Northridge Earthquake, which damaged four major freeways in the Greater Los Angeles area, are numerous. Schmitt [1] reported that the transportation system in Los Angeles 
demonstrated enormous resiliency following the earthquake, as half of all known commuters in Los Angeles and $80 \%$ of those in the direct earthquake-affected zone were able to make some adjustment in their travel. Similarly, Giuliano and Golob [2] reported that most residents adjusted to crisis conditions by modifying routes and travel-time expectations, while avoiding discretionary trips within damaged areas. Willson [3] examined the impacts of the earthquake on Los Angeles County trucking firms, and reported the impact, though initially widespread, was relatively short-lived; he concluded that such impact was far less than expected on account of timely restoration of highway access, made possible by redundancies in the road network and prompt action on the part of public agencies.

All these reports concluded that the Northridge Earthquake was thus a relatively moderate event. However, of the firms reporting earthquake loss, $43 \%$ stated that some portion of their business loss was due to transportation damage [4]. Moreover, Boarnet [4] points out that both wholesale and retail sales firms are likely more vulnerable to transportation losses, over manufacturing firms.

Considering the overall risk of a major seismic event in Greater Tokyo, we must reconsider such impact factors in the greatest possible detail, in view of the fact that Tokyoites rely far more heavily on public transport than do Angelinos. In addition, since business and commercial activities are dominant, the potential impact of any such disaster in Tokyo should be regarded as differing from that of the Northridge Earthquake.

Given this background, interest has increased, especially after the Kobe (1995) and Tohoku (2011) Earthquakes, in business continuity plans (BCPs) expected to minimize damage and promote the continuity of business activities and an early recovery in the aftermath of any severe earthquake [5]. This has led in turn to calls for district continuity plans (DCPs) that seek to coordinate the BCPs of local enterprises and strengthen their mutual compatibility, assist stranded commuters, and promote early recovery and rehabilitation of the community at large [6]. Kadam [7] also suggests the importance of so-called personal business continuity plans (PBCPs), aimed at reducing anxiety levels and restoring the status quo as quickly and effortlessly as possible. We have used the term "community activities" to designate the collective daily activities of residents and the economic activities of enterprises. The ability of workers to commute to their jobs is a sine qua non in the support of overall community activities and post-disaster revitalization efforts. Such worker mobility exercises a disproportionate influence in commercial zones of large conurbations, where workers by far tend to outnumber residents. Nevertheless, it is likely that most public transport will be paralyzed for a significant interval following a major seismic event, so it is not easy to predict what proportion of workers may actually intend to go to work (commuting intention) or whether it will be possible for any or all to implement such an intention.

A good deal of research has been committed to stranded commuters and walking-home behavior [6,8], but virtually none analyzes the more generalized post-disaster commuting behavior of the working population, even if certain studies have addressed this concern indirectly. For example, Sekizawa [9] conducted a survey to determine how many persons involved in disaster preparedness programs actually responded to emergency summons during an earthquake, while Takahashi [10] developed a system for estimating the number of essential emergency personnel who may be expected to be on hand for assistance in the event of a disaster. Regarding traffic conditions, Iida et al. [11] described fundamental issues of existing traffic management systems with regard to actual traffic conditions following the Kobe Earthquake (1995). Although these authors proposed an improved concept for post-earthquake traffic regulation, their scheme focuses only upon the immediate post-disaster environment and context. Hence, all 
previous studies have essentially addressed only the success or failure of specific disaster preparedness measures within the broader framework of overall risk management.

By contrast, in this regard Osaragi and Tamano [12] made use of a questionnaire-based survey of employed persons to construct a model for estimating the probabilities of sustainable business commuting from the twin viewpoints of commuter intention and actual mobility (e.g., endurance in walking or bicycling to work) in the aftermath of a large-scale seismic event. In the present article, we extend the discussion about commuting behavior after a hypothetical large seismic event in Greater Tokyo. Namely, we attempt more precise discussion about commuting intention from the viewpoint of respondent attributes and commuting times under ordinary conditions. We also clarify the characteristics of commuting difficulty, which varies in accordance with personal attributes as well as local geographical features. Especially, the possible reasons for heterogeneous spatial distribution of commuting difficulty are demonstrated, and we debate the principal issues, which should be considered on the establishment of local BCPs and DCPs. One more original contribution of this article lies in its implications for quick emergency response and recovery. We discuss how and why the percentages of commuting difficulty alleviate after the restoration of railway service.

\section{Questionnaire-Based Survey and Tabulation}

\subsection{Outline of Questionnaire}

Our survey was conducted via the Internet (using the Internet Survey System produced by Macromill, Inc.) from 23 December 2010 to 28 December 2010. Targeted respondents were individuals working within the twenty-three wards of the Tokyo Metropolitan Area, and the effective real number of respondents was 1266. Sampling was imposed to adjust for a real-life proportion of age cohort, gender, and actual commuting times. In particular, we prorated industry sector and occupation among respondents to agree with that of the most recent Tokyo census. Since no extreme deviation relating to any of these attributes was observed, any effective bias imposed by our limitation to Internet users was considered negligible. The number of respondents with their attributes are shown in Table 1.

Table 1. Respondents attributes of questionnaire survey on commuting behavior.

\begin{tabular}{ccccccc}
\hline Actual Commuting & Gender & \multicolumn{5}{c}{ Age Cohort } \\
\cline { 3 - 7 } Times & Male & 42 & 62 & 57 & 47 & 21 \\
\multirow{2}{*}{$0-10$} & Female & 47 & 42 & 57 & 47 & 21 \\
& Male & 62 & 47 & 52 & 42 & 16 \\
$21-30$ & Female & 37 & 26 & 57 & 26 & 9 \\
& Male & 62 & 52 & 42 & 37 & 11 \\
$51-60$ & Female & 26 & 21 & 16 & 16 & 6 \\
& Male & 31 & 26 & 26 & 26 & 9 \\
$81-90$ & Female & 8 & 6 & 6 & 6 & 3 \\
& Male & 8 & 8 & 8 & 8 & 8 \\
& Female & 4 & 6 & 6 & 3 & 0 \\
\hline
\end{tabular}


The Tokyo Metropolitan Government Bureau of General Affairs estimates that following a major earthquake centered in Tokyo [13], fire would consume 800 or more structures resulting in 20,000 or more fatalities (supposing a 6.9 magnitude quake occurring at 6:00 p.m. in winter with a wind of $6 \mathrm{~m} / \mathrm{sec}$ ). We asked respondents to answer whether they would resume their round-trip commute between home and place of work within one week to one month after the event, assuming the following three conditions: (1) neither you nor other family members are injured; (2) damage to your own house is minor; and (3) damage to your workplace is minor.

Furthermore, in order to ensure uniform post-earthquake conditions and a similar scale of damage, representation among respondents, nine photographs taken after the Kobe Earthquake (1995) were provided online. In addition, the following hypothetical information was supplied: (1) large areas are subjected to catastrophic damage; (2) numerous buildings have collapsed; (3) large numbers of wooden buildings have been destroyed by fire; (4) lanes and alleyways are blocked by collapsed buildings; (5) restoration of train service is not yet foreseen; (6) no other public transport is available; and (7) temporary scaffolding is demonstrably inadequate.

In the questionnaire placed on the Internet, respondents were asked: (1) the locations of residence and workplace; (2) work-related information (industry sector, occupation, and employment status); (3) usual means of commuter transport, commuting times for each means, and the number of bicycles per household. They were also asked the following items, in the event of a total post-quake paralysis of public transport: (4) upper time limit for completion of a round-trip between home and workplace; (5) the respondent's ability to commute on foot or by bicycle; (6) whether or not a bicycle would offer a viable means for commuting; and (7) disaster-preparedness measures at the workplace and instructions regarding post-disaster commuting.

\subsection{Basic Statistics}

Comparisons between disaster-preparedness mandates issued by respondents' employers at the workplace ranged by industry sector show that approximately $80 \%$ of government workers have received protocols or instruction, which indicates a higher disaster-prone awareness than in most other sectors (Figure 1). Approximately $70 \%$ of civil servant respondents have been instructed to come to work after a severe earthquake, whereas approximately $60 \%$ of private-firm employees received no particular instructions in that regard (Figure 2). Scrutinizing these by occupation, we found little difference between the instructions regarding continuing responsibility for those in administrative or managerial positions, despite such workers' key importance in maintaining operations, if compared to instructions having been issued to lower-echelon employees. Examining the data by industry sector, we found that approximately $30 \%$ of healthcare and welfare personnel have been instructed to return to work. This percentage is the second highest after government workers.

Workers' fixed commuting intentions naturally dwindle and thus trend lower overall as commute-time increases. Therefore, in addition to queries about extended acceptable commuting times, we also evaluated the percentage of respondents intending to continue to travel to work (commuting intention) against commuting times under usual conditions (Figure 3). Those receiving instructions to return to work (Case (A)) displayed higher commuting intentions than those receiving no such instructions (Case 
(B)). However, both groups predictably show diminishing percentage curves over increases in usual commuting time.

[Industry sector]

Fovemment

Manufacturing

Communications and transport

Healthcare and welfare

Construction

Wholesale and retail trade

Services

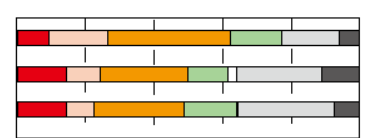

BCP (Business Continuity Plan) formulated, or being developed

$\square$ Other disaster prevention plan formulated, or being developed

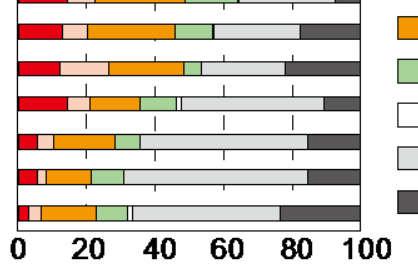

Performing a regular emergency drills

Taking measures to damage of equipments and buildings

$\square$ Other

$\square$ Not consider

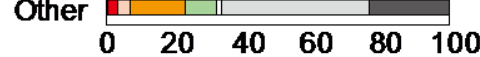

Not sure

The proportion of respondents (\%)

Figure 1. Disaster-preparedness measures on the part of business firms noted in response.

[Employment status]

Tenured civil servant

Business executive

Full-time clerical

Full-time professional

Full-time (all others)

Freelance professional Self-employed

Part-timer(and temporary)
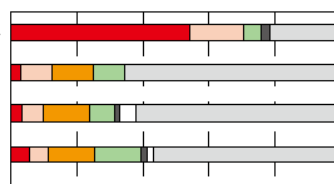

$+11$

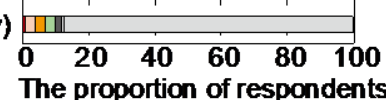

[Industry sector]

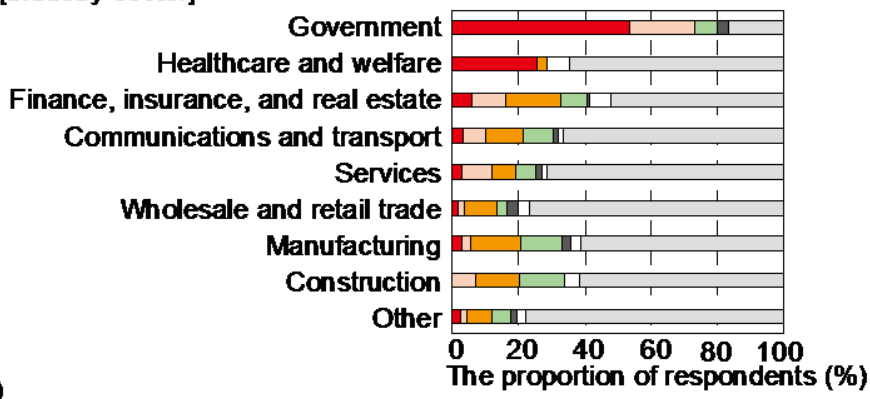

[Occupation]

Administrative and managerial

Professional and engineering

Clerical

Transport and sanitation

Services (other)

Sales

All others
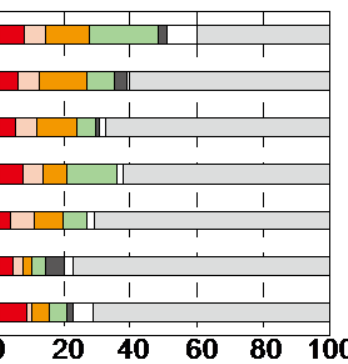

The proportion of respondents (\%)
[Instructions by company]

Retum to work as quickly as possible, even if it's not a normal working day

$\square$ Retum to work as usual, if it's a normal working day

$\square$ Wait at home until getting an instruction

$\square$ Need not retum to work, if transportation-means are not available

$\square$ Need not retum to work, regardless of the situation

$\square$ Other

$\square$ Not particularly instructed

Figure 2. Disaster-preparedness instructions by employment type, job, and skill categories.

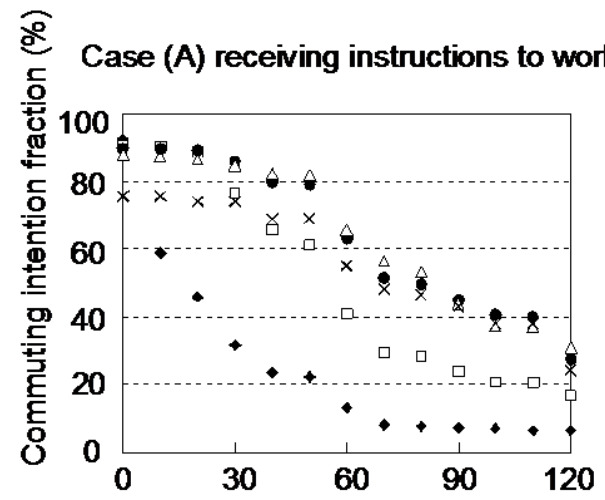

Increment of commuting time (minutes)

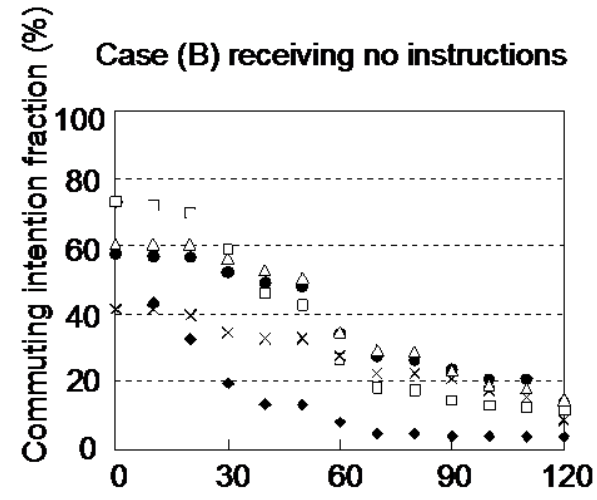

Increment of commuting time (minutes)
Ordinal commuting time

0 - $10 \mathrm{~min}$.

$\square 21$ - 30 min.

- 51 - 60 min.

$\triangle 81-90 \mathrm{~min}$

$\times 111-120 \mathrm{~min}$.

Figure 3. Ratio of commuting intention plotted against hypothetical acceptable commutes. 


\section{Joint Post-Disaster Mobility Model}

\subsection{Model Structure}

Public transport is often paralyzed after a severe earthquake. Lack of public transport obstructs and slows usual commutes and forces individuals to modify their ways and means of getting to work. In addition to stated or unstated commuting intentions, more or less randomly imposed conditions of locomotion impact ability to commute. Therefore, our model of commuting intention was combined with a model of alternate locomotion choices and integrated as a joint post-disaster mobility model.

\subsection{Commuting Intention}

The percentage of workers with an expressed commuting intention was directly assessed from the survey data mentioned in the previous section. As samples were nonetheless limited, a reliable array of commuting intention percentages proved difficult to construct owing to the wide divergence of respondent attributes. Besides, in case that we employ traditional models, respondents have to answer a large number of questions composed of a large choice set. It forces too much load to respondents. Therefore, we employed Neural Network Model (a three layer perceptron), which is very flexibly applicable for a large number of conditions, and can distinguish data that are not linearly separable [14,15]. A threelayer perceptron utilizes a supervised learning technique called backpropagation for training the network $[16,17]$, and was actually trained using the raw survey data and employed to model these percentages. Figure 4 provides the details of the three layer perceptron in the case that occupation was used as input data of professional data.

Five factors assumed to affect commuting intention were employed as input signals: (1) gender; (2) age; (3) professional data (industry sector, occupation, and employment status); (4) commuting time under usual conditions; and (5) estimated post-disaster commuting times. The replies of respondents expressing their commuting intentions were input for both Case (A), having received instructions to continue work, as well as for Case (B), receiving no particular such instruction. Six models of commuting intention corresponded to the six combinations of input signals resulting from three classes of professional data multiplied by cases (A) and (B) combined under teaching signals (input as the intention to commute or not). Initial weights between neurons are determined using a random number. The backpropagation algorithm was used for minimizing the differences between the output of the model and answers of respondents. Learning is complete when the relative rate of change of the sum of squared errors of prediction is less than 0.0001 .

Next examined were workplace instructions with regard to increases in commuting time as related to the commuting intention percentages predicted by the foregoing model (Figure 5). If the increase in commuting time was no more than 30 minutes, little difference by type of employment was found in Case (A). However, in Case (B), the commuting intention percentage was low, except for civil service employees. Likewise, a survey of occupations revealed no great difference in the commuting intention between those in administrative and managerial positions, who thus bear responsibility for continuity of operations, and all other employees. An examination by industry sector showed that government employment yielded a high commuting intention percentage, and this was notably higher than that in other job types when no disaster-preparedness instructions had been forthcoming in the workplace. 
input data

(1) gender (2 neurons)

(2) age (6 neurons)

(3) professional data: occupation (7 neurons)

(4) commuting time under usual conditions ( 1 neuron)

(5) estimated post-disaster commuting times (1 neuron)

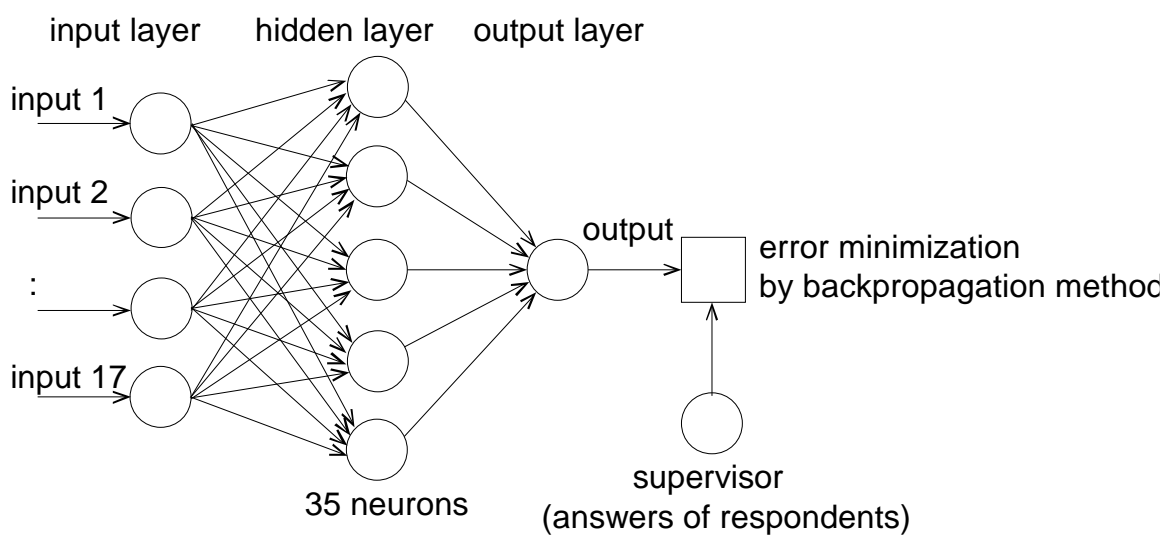

Figure 4. Structure of commuting intention: three-layer perceptron.

[Employment status] Case (A) receiving instructions to work
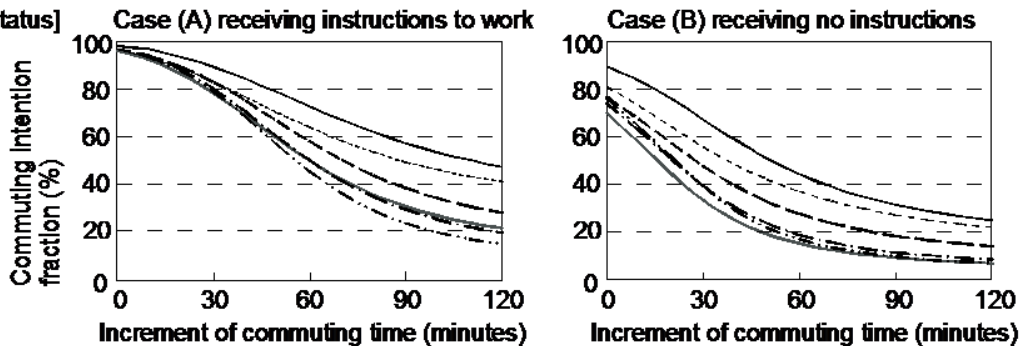

[Employment status]

- Tenured civil servant

-...- Business executive

- - Ful-time employee

-.. Freelance professional

- Self-employed

-.. Part-timer(and temporary)
[Occupation]

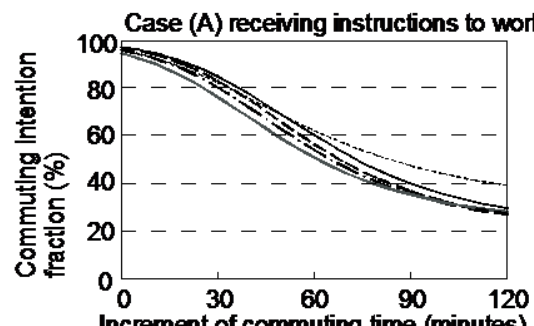

[Industry sector]

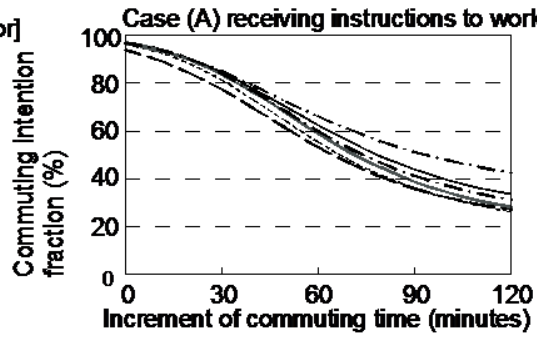

[Commuting time]

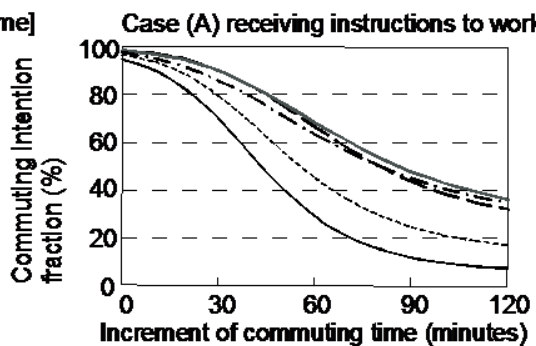

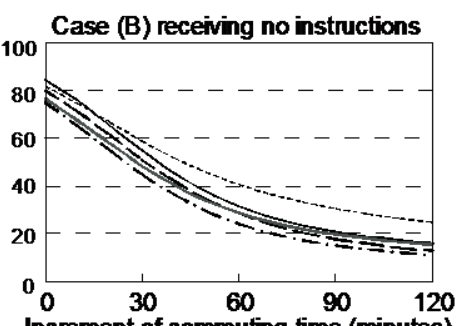

[Occupation]

Administrative and managerial

_. - Professional and engineering

- - Clerical

-..-. Transport and sanitation

- Services (other)

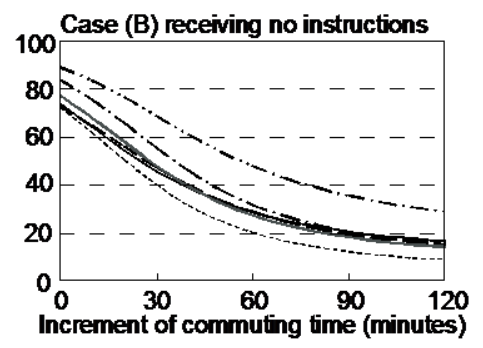

$$
\begin{array}{ll} 
& \text { [Industry sector] } \\
\ldots . . & \text { Govemment } \\
\ldots .- & \text { Finance, insurance, and real estate } \\
\ldots . . & \text { Manufacturing } \\
\text {-- } & \text { Communications and transport } \\
\text { - } & \text { Construction } \\
\hline & \text { Wholesale and retail trade }
\end{array}
$$

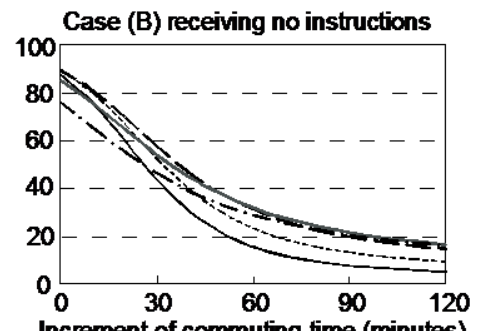

[Ordinary commuting time]

0 - $10 \mathrm{mn}$

… $21-30 \mathrm{~min}$.

- $51-60 \mathrm{~min}$.

- $81-90 \mathrm{~min}$.

- .. $111-120 \mathrm{~min}$.

Figure 5. Estimated value of commuting intention percentages expressed in terms of employment conditions and ordinary commute times. 


\subsection{Locomotion Model}

When public transport is knocked out and people must travel either on foot or by bicycle, actual travel distances tend to increase. This impact on worker mobility needs to be further investigated. Therefore, a second model was constructed to describe mobility in commuting modes based on the answers to questions about travel on foot or by bicycle in the event of a severe earthquake. Figure 6 provides details of this model. Data from a survey of physical strength and endurance issued by the Ministry of Education, Culture, Sports, Science and Technology (MEXT) [18] was applied to respondent attributes (gender and age) to estimate the probability that a respondent would be able to walk or cycle the required commuting distance. This provided a model for estimating workers' mobility.

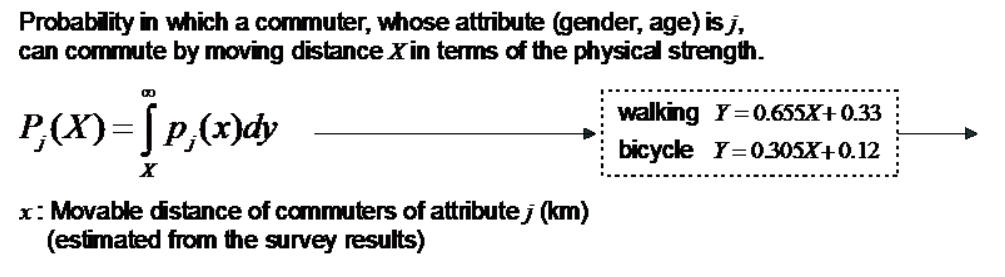

$$
P_{j}(X)=\int_{Y(X)}^{\infty} q_{j}(y) d y
$$

$y$ : Physical fitness score of attribute $\mathrm{j}$ taken from "Physical fitness and exercise capability Survey" by Education, Culture, Sports, Science and Technology (2006)
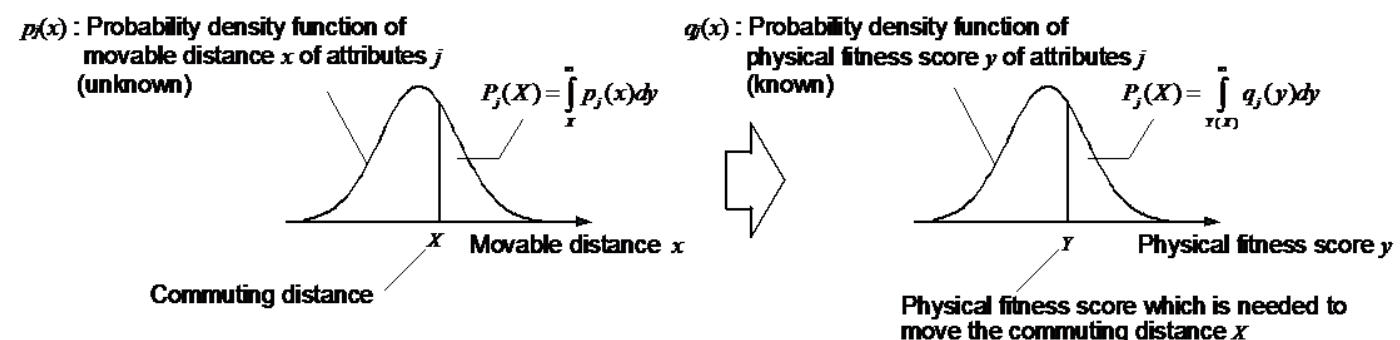

Figure 6. Component analysis of locomotive capability model.

\section{Estimating Overall Worker Commuting Ability}

\subsection{Means of Commuting after A Severe Earthquake}

Modes of commuting after a severe earthquake are largely dependent on damage and subsequent repairs to roadways and railroads; it is difficult, if not impossible, to make an exact prediction of damages, let alone specify any single set of outcomes. Our study therefore envisioned multiple situations involving travel modes and degrees of recovery and attempted to evaluate the ability of workers to commute in each situation. Next, the influence of locomotive choices and degree of infrastructural recovery on a worker's ability to commute was dealt with. Specifically, respondents were asked to imagine a modified commuting experience under the following five conditions: (1) they could only walk or use a bicycle; (2) they could walk, cycle, or drive; (3) they could walk, cycle, or take a bus; (4) they could walk, cycle, take a bus, or drive; and (5) they could walk, cycle, or make use of restored rail infrastructure. The degree of infrastructural restoration was also considered for automobiles, buses and trains. Aside from condition (5), which assumes viable rail service, rail transport was not a given option. Parking would naturally have to be available in order to drive to work, so it was assumed for conditions (2) and (4) that only respondents who drive to work on a regular basis could also drive post-quake. For 
bus commutes, areas where bus travel was possible were extracted from the PT data and it was assumed that buses would only be used in those areas that had enjoyed bus service before an earthquake occurred.

\subsection{Procedure for Predicting Mobility}

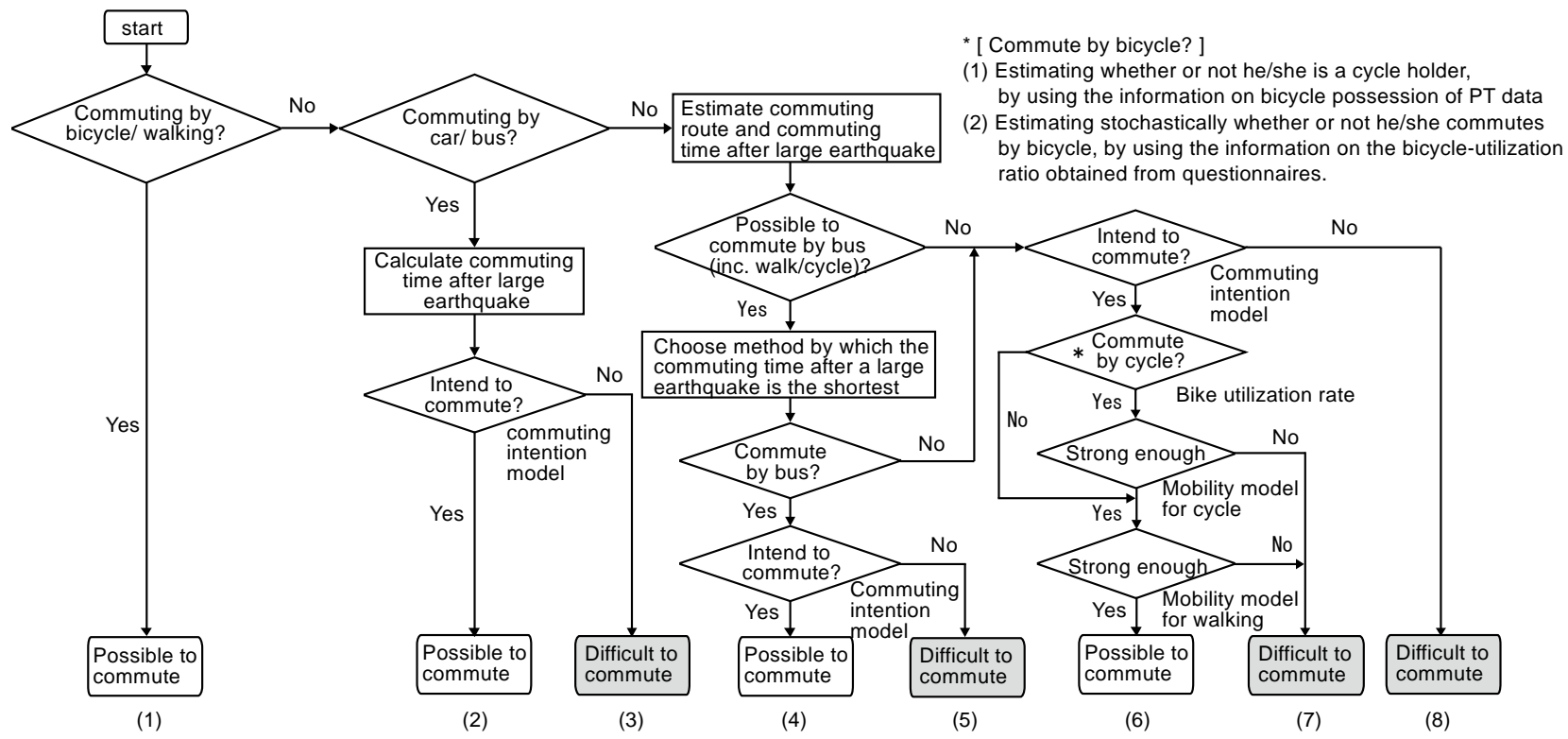

[ Classification of commuters ]

(1): possible to commute as usual

(2): usual means (with commuting intention)

(3): usual means (no commuting intention)

(4): take a bus (with commuting intention)

(5): take a bus (no commuting intention)

(6): walk or cycle (with commuting intention and ability)

(7): walk or cycle (with commuting intention, no ability)

(8): walk or cycle (no commuting intention)
[ Definition of difficulty in commuting ]

Difficulty in commuting based on residential zone

$$
R_{h i}=\frac{n_{h i}}{N_{h i}} \cdot 100 \text { (\%) }
$$

Difficulty in commuting based on commuting zone

$$
R_{o i}=\frac{n_{o i}}{N_{o i}} \cdot 100 \text { (\%) }
$$

\footnotetext{
$n_{h i}: \begin{aligned} & \text { Number of residents in zone i with difficulty } \\ & \text { in commuting }\end{aligned}$

$N_{h i}$ : Total number of residents living in zone $i$

$i$ : Number of people working in zone i with difficulty in commuting
}

$N_{o i}$ : Total number of people working in zone $i$

Figure 7. Flowchart assessing overall ability of workers to commute from home to workplace after a severe earthquake as determined in this paper.

Here, let us assume condition (4) of the available means of transport (walking, cycling, taking a bus, or driving) as an example in order to explain the procedure for calculating the general ability of workers to commute post-quake (Figure 7). If the respondent had commuted under ordinary conditions only by walking or cycling, he/she is least likely to be affected by any paralysis of public transport. Therefore, all such respondents were assumed able to continue getting to work more or less as before. If the respondent had commuted by car or bus, his/her commuting intention was estimated using our model based on commuting times accounted for by increased roadway congestion in the relevant zones. However, the ability to commute for workers who walk or cycle to work was estimated using both the model of commuting intention and the mobility model. These approaches jointly provide estimates of the ability of the entire corpus of workers to continue commuting, thus providing estimates for the percentages of workers who would find it more or less difficult to accomplish their post-quake commute. The model of commuting intention only simulates mental processes attributed to the respondent with respect to commuting time, so it is possible that more workers would decide against going to work than the number predicted here. The number of people who find it difficult to go to work compared to the total number of workers is defined as the "percentage having difficulty in commuting". Hereafter, the 
number of workers commuting to a given working zone who find it difficult to go to work compared to the total number of workers there is referred to as the "employment-zone-based percentage having difficulty in commuting" and those workers living in a given residential zone who find it difficult to go to work compared to the total zone population is referred to as the "residential-zone-based percentage having difficulty in commuting".

\subsection{Method for Predicting a Commute Path on Foot, by Bicycle, or by Train}

To assess the ability of workers who ordinarily get to work on foot, by bicycle, or by train, we had first to ascertain a commuting route and then estimate the resulting distance traveled and commuting time under conditions in which public transport was unavailable. Therefore, a simulated database of the existing transportation network was created integrating road and rail, and this database was used to anticipate ordinary commuting routes. Since it would consume immense computing time if the entire roadway system for the Tokyo region were to be simulated, the roadway data set and existing main thoroughfare data were constructed by using straight-line distances between residential location and workplace location [19], according to a two-tier procedure as illustrated in Figure 8.

Dijkstra's algorithm was applied to the transportation network database to deduce commuting routes with the lowest travel times, and travel distances on foot and by bicycle were thus found (Figure 9). When residential location and workplace location were situated in the same "zone" (a spatial unit for tabulation drawn from the PT data), the assumed time required for travel between these two points was estimated by performing 1000 calculations of the travel time between two random points in the requisite zone and then taking the mean time-and-distance.
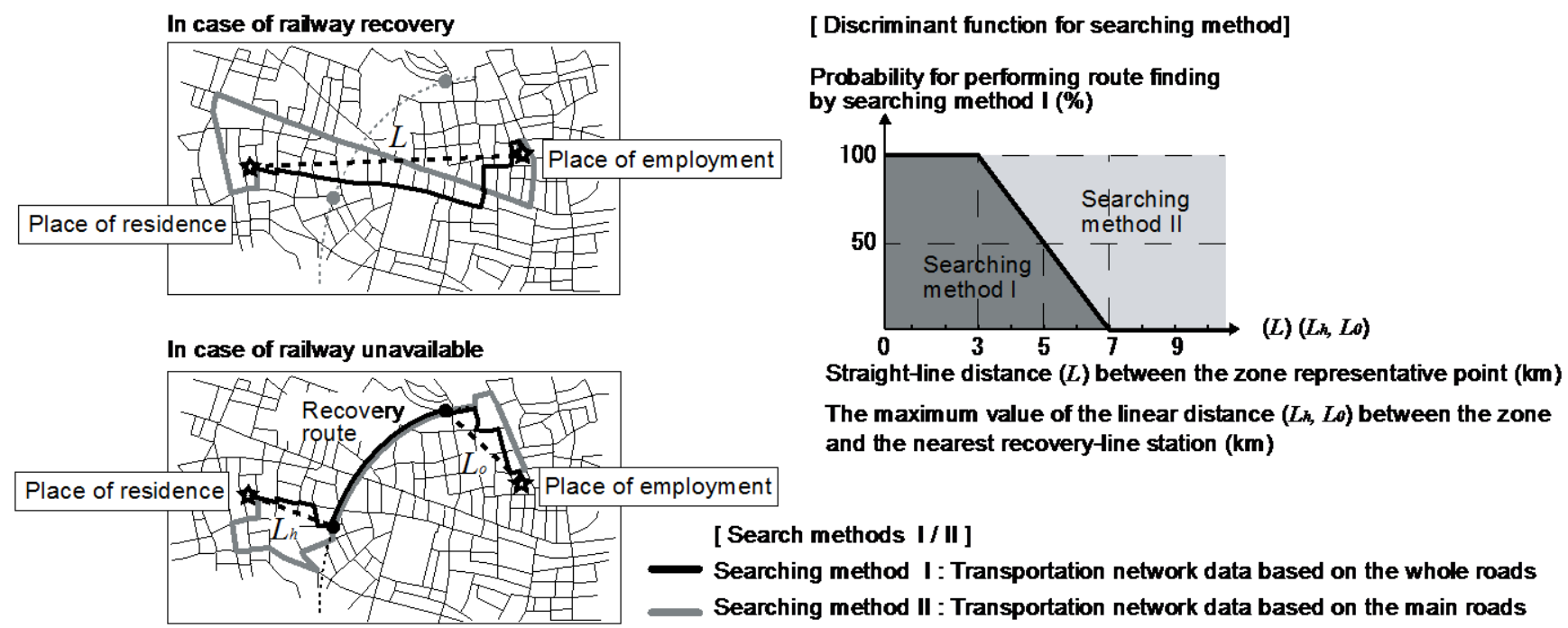

Figure 8. Method for discriminant selection of search methods I and II. 


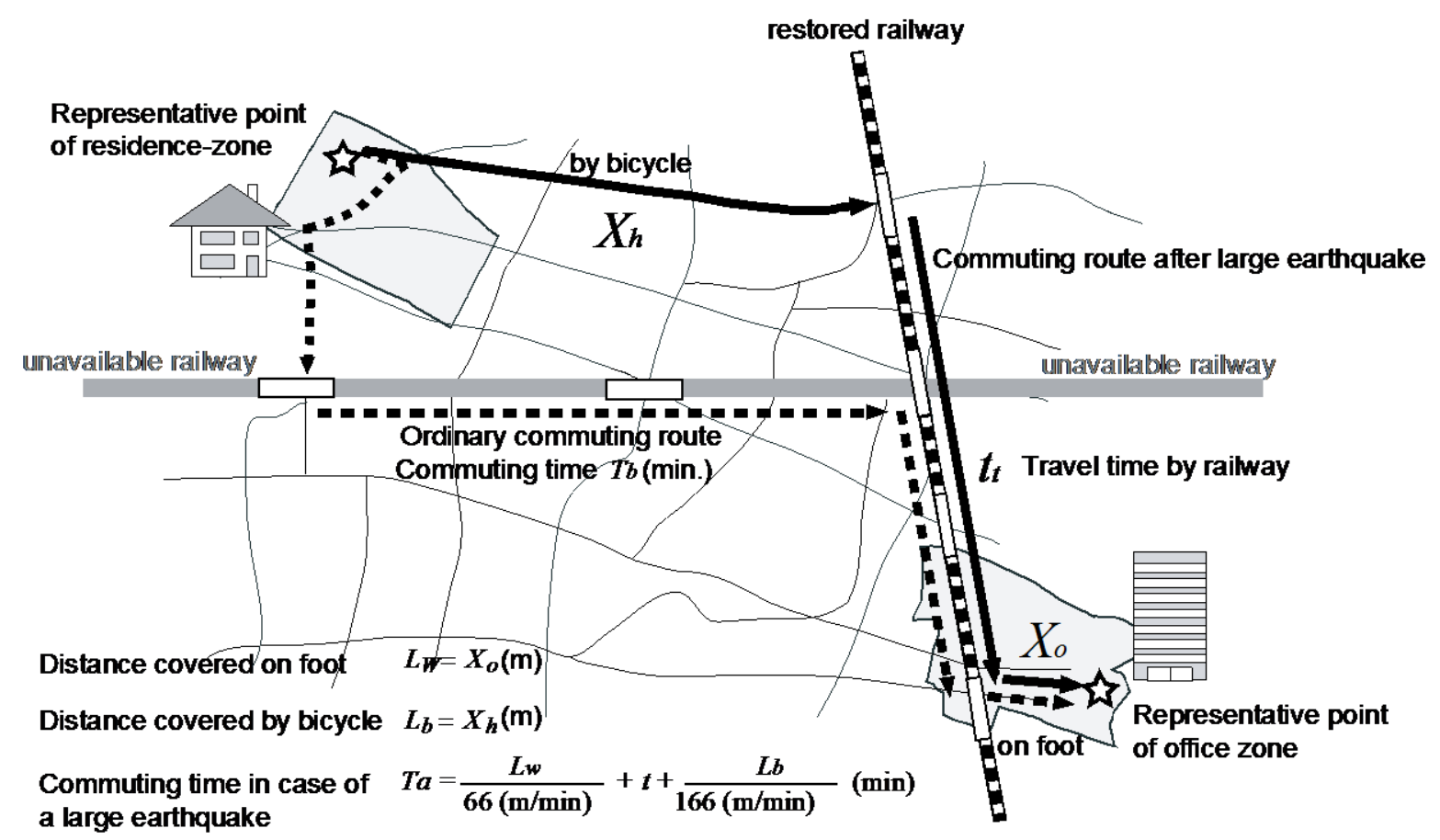

Figure 9. Method for estimating commuting routes on foot and by bicycle.

\subsection{Method for Predicting Commuting Time If Driving or Taking a Bus}

Numerous roadways may be blocked by debris from collapsed buildings and fires following an earthquake. This factor had to be accounted for, owing to the delays in commuting times imposed upon travel by car or bus. There is no way to describe where and to what degree actual delays will occur, but we are able to detect the overall information needed to assess a worker's ability to commute to work, i.e., the commuting time from home to workplace. The procedure depicted in Figure 10 accounts for overcrowding of roadway infrastructure in various parts of Tokyo under usual conditions; by extension, a similar model can be used to predict extended commuting times after a severe earthquake.
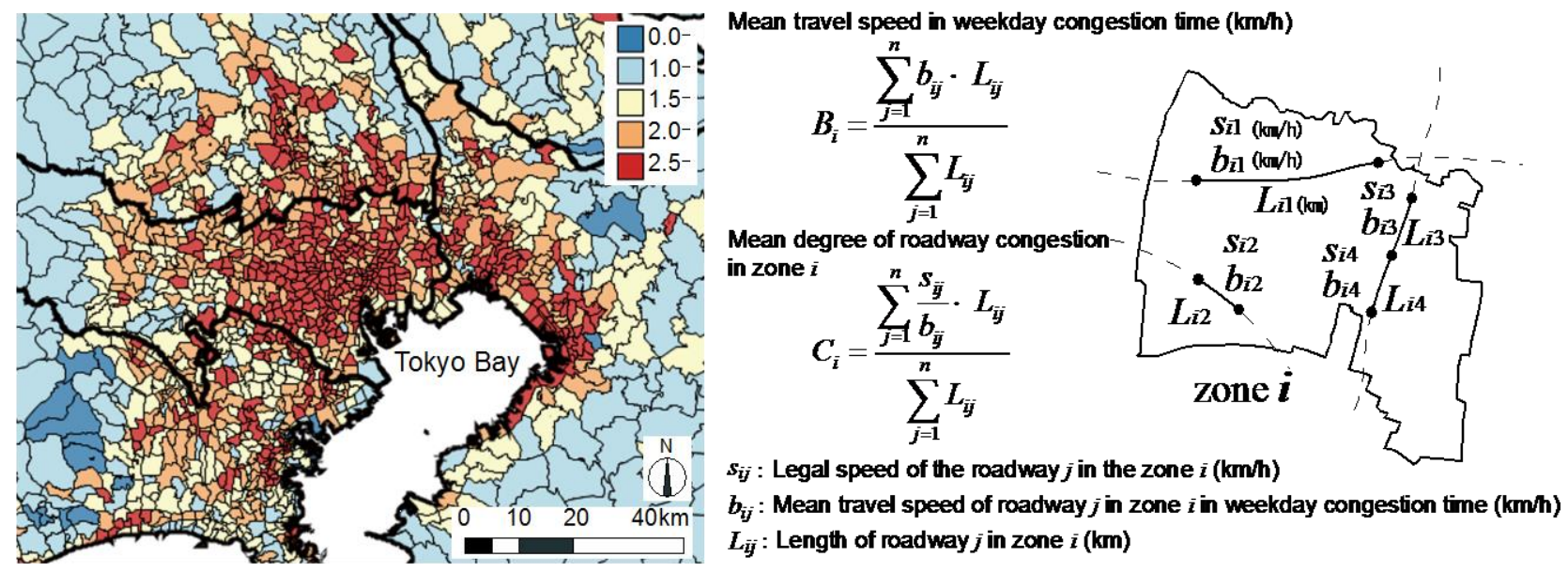

Spatial distribution of mean degree of roadway congestion

Figure 10. Method for assessing daily road congestion in the Kanto Region under usual conditions. 
In Figure 10, the legal maximum speed and speeds impacted by traffic congestion under usual conditions reported in the Road Traffic Census by the Ministry of Land, Infrastructure, Transport and Tourism [20] are employed to calculate $C_{i}$, the mean degree of roadway congestion. It can be seen from the spatial distribution of the mean degree of roadway congestion that throughout the region the closer one is to the center of Tokyo, the greater the tendency for congestion to occur. Likewise, the more likely any locale is to become congested at usual times, the greater the slowing after a disaster. Assuming that mean post-disaster travel speeds $A_{i}$ are proportional to the mean degrees of roadway congestion under ordinary conditions $C_{i}$, the values in zone pairs $\left(Z_{1}, Z_{2}\right)$ were then used to generate ratio $\alpha\left(Z_{1}, Z_{2}\right)$ and create a further model (Figure 11).

Mean post-disaster travel speeds after a disaster (assumption)

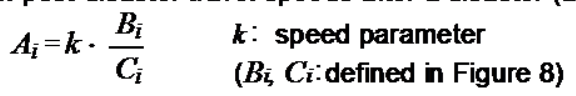

Ratio of travel time after a disaster and at normal time

$$
\alpha_{i}=\frac{B_{i}}{A_{i}}=\frac{1}{k} \cdot C_{i}
$$

Travel-time ratio after a disaster when moving from zone $Z_{1}$ to zone $Z_{2}$

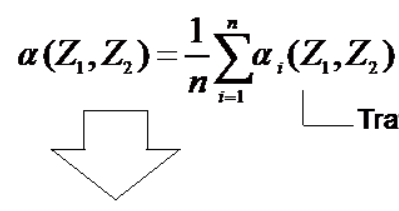

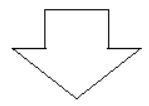

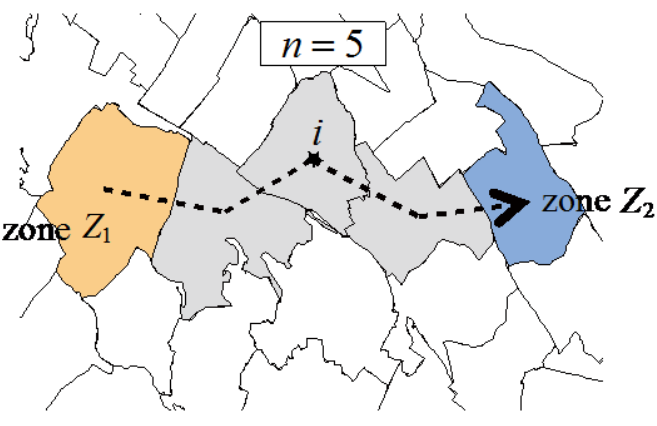

Travel-time ratio in zone $i$ on the line from zone $Z_{1}$ to zone $Z_{2}$.

Commuting time after a large earthquake (min)

$$
T_{a}=\alpha\left(Z_{1}, Z_{2}\right) \times T_{b} \quad T_{b}: \text { normal commuting time (min) }
$$

Figure 11. Method of assessing commuting times after a major earthquake by taking into account the increased degree of road congestion.

\section{Spatial Distribution of Percentages of Workers Experiencing Difficulty in Commuting}

\subsection{Percentage Having Difficulty in Commuting Based on Available Means of Transport}

Percentages of commuting difficulty were estimated for each available means of transport. The overall percentages fell throughout the Tokyo region in line with the increasing number of available means of transport. Figure 12 divides these populations into workers who had received instructions to return to work and those who had not (namely, Cases (A) and (B) in Section 2.2). Case (B) demonstrated a higher percentage commuting difficulty, but no great difference was found between the spatial distributions of Cases (B) and (A). Our observations regarding the regional characteristics of the percentages having difficulty in commuting below are thus limited to workers in Case (A).

The percentage having difficulty in commuting was calculated for the available means of transport in conditions (1) through (4), as specified above. The spatial distribution of these percentages is shown in Figure 13. Taking a residential-zone basis. Condition (1), $80 \%$ of workers estimated as no longer able to commute if forced to either walk or cycle lived in Machida, Tokyo or in the independent cities of Kawasaki and Yokohama (both Kanagawa Prefecture), or in the suburbs of other relatively distant cities. 
Condition (2), the percentage having difficulty in commuting dropped considerably in the walking/cycling/driving condition, in which the respondent was allowed use of an automobile. However, the percentage having difficulty in commuting remained high (some 70\%) in the west of the twentythree central wards of Tokyo and in Chiba Prefecture to the East, as well as in Machida, Tokyo, in Kawasaki, and in Yokohama. In Condition (3), a less sizeable drop than under Condition (2) was generally found in the walking/cycling/busing condition, though the percentage decrease of those having difficulty in commuting was greater on the west side of Tokyo, in Yokohama, and in certain other locations. This can be attributed to a relatively high dependence on buses for transportation in those locations under ordinary circumstances. Condition (4), under the walking/cycling/driving/busing condition, the number of regions in which the percentage having difficulty in commuting was $70 \%$ decreased significantly, but remained elevated at $70 \%$ in Kawasaki and in the western part of Chiba Prefecture; the percentage having difficulty in commuting remained at $80 \%$ in some parts of Kawasaki. Even though these regions appear to have relatively good access to central Tokyo and central Yokohama, it was apparent that access to workplace location is severely strained if trains are not running.
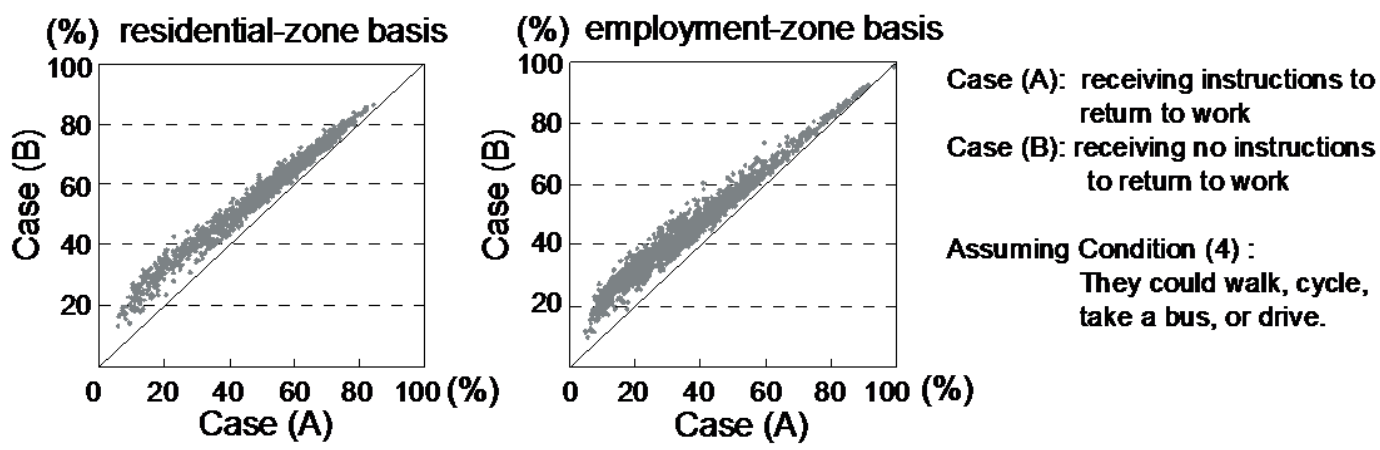

Figure 12. Percentages of commuting difficulty according to residential and employment zones and based on reception/non-reception of instructions to return to work.

Taking an employment-zone basis: Condition (1), a high number (80\%) of those who described themselves as no longer able to commute if forced either to walk or cycle worked in central Tokyo, along the bay, or in the suburbs of neighboring prefectures. However, taking Condition (2), the percentage having difficulty in commuting was much lower under the walking/cycling/driving condition for locations more sparsely served by railroads and thus normally more dependent on automobiles. In Condition (3), the percentage having difficulty in commuting dropped under the walking/cycling/busing condition among those working in Yokohama; Hachioji, Tokyo; Machida Tokyo; and others, where bus dependence is high, while it remained $70 \%$ in central Tokyo. In Condition (4), even under the walking/cycling/driving/busing condition, the percentage having difficulty in commuting remained $70 \%$ in central Tokyo; in other words, even if it remained possible to drive or take a bus, if trains were not available, the fraction having difficulty in commuting was not likely to diminish among those working in central Tokyo. 


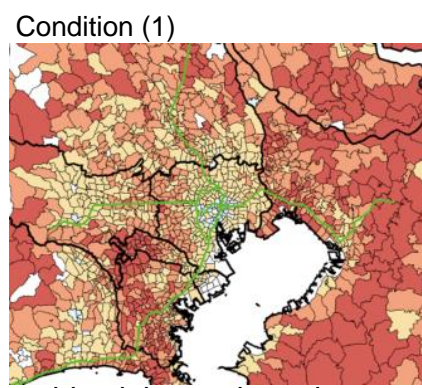
Condition (2)

Condition (3)
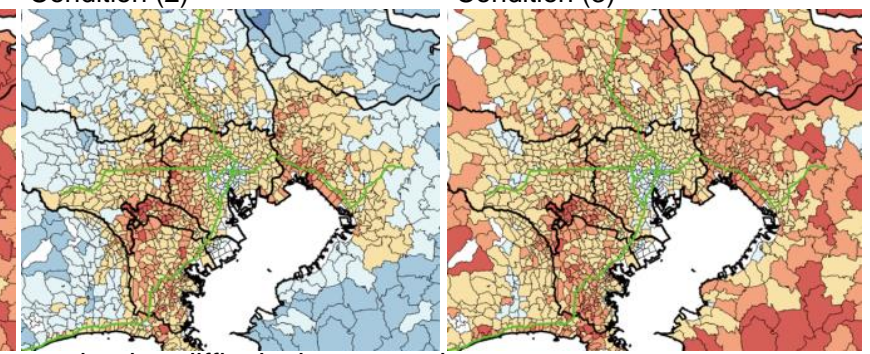

Condits

residential-zone-based percentage having difficulty in commuting
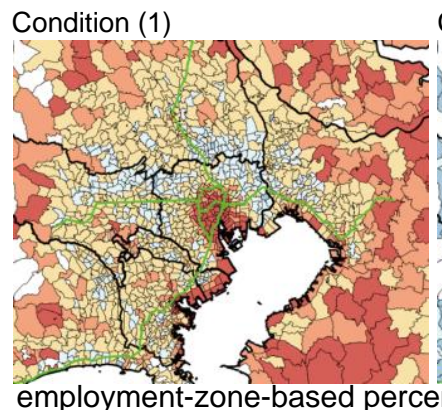

Condition (2)

employment-zone-based percentage having difficulty in commuting
Condition (4)

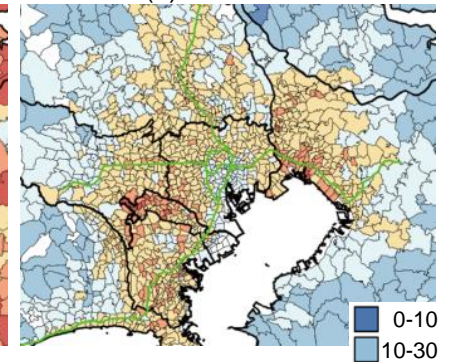

Condition (4)

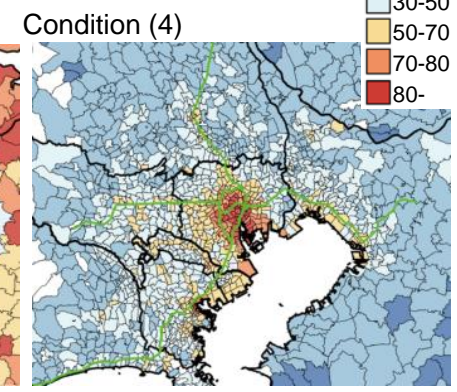

Figure 13. Spatial distribution of percentages of commuting difficulty as impacted by four hypothetical conditions of available transport according to residential and employment zones.

Next, we examined how the speed parameter $k$ for cars and buses affected the percentage having difficulty in commuting under Condition (4), where walking/cycling/driving/busing was allowed (Figure 14). The percentage having difficulty in commuting fell as $k$ increased (in other words, as the effect of congestion decreased). This is because of the overall high dependence on cars in the suburbs. However, the twenty-three wards of Tokyo and regions with working populations exceeding 40,000 showed a smaller decrease than did the overall Tokyo region. Specifically, the percentage having difficulty in commuting was approximately $80 \%$ in the twenty-three wards of Tokyo, but only some $65 \%$ in regions with working populations exceeding 40,000. The reason the percentage failed to decrease in spite of greater possible automobile speeds was that under normal conditions transportation in the center of Tokyo has a relatively low dependence on cars.

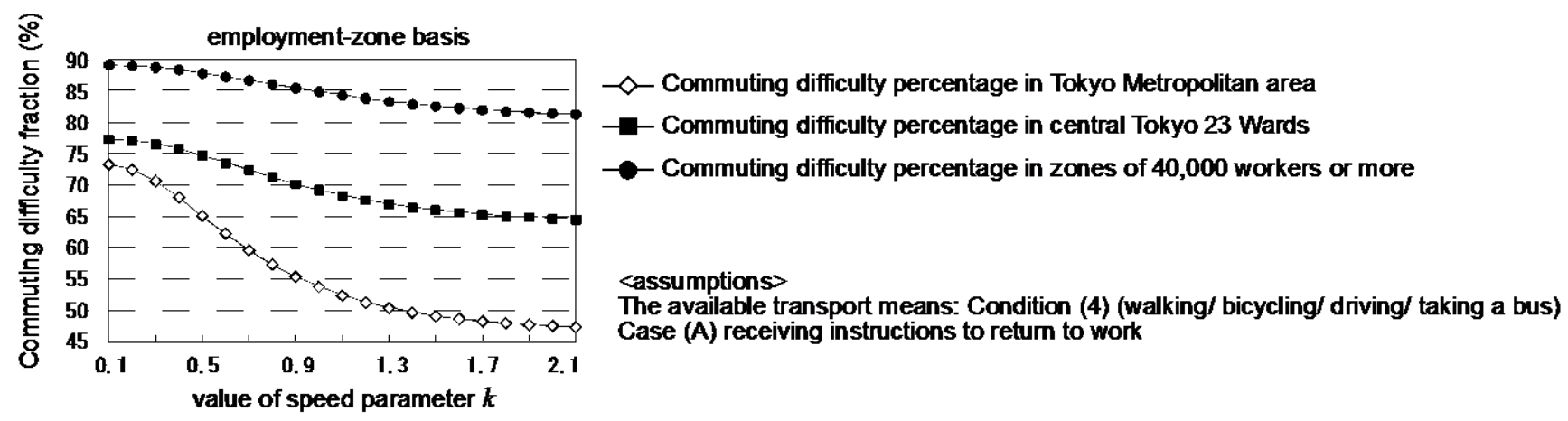

Figure 14. Ratios between speed parameter $(k)$ and percentages of commuting difficulty. 


\subsection{Gender Differences in Percentages Having Difficulty in Commuting}

The percentage having difficulty in commuting was estimated for the two genders and examined for variations in mode of travel and distance from the center of Tokyo (Chiyoda 1-1-1, or the Imperial Palace) to a worker's residential location (Figure 15). Beginning with the residential-zone basis, women presented a higher percentage having difficulty in commuting than men when residing within $12 \mathrm{~km}$ of the center. This can be attributed to women having a lower commuting intention generally and also a lower self-perceived and/or age-based mobility than men. At distances greater than $12 \mathrm{~km}$ from the center, however, this trend was reversed; men showed a higher percentage of commuter difficulty. This may well be because a greater percentage of those men working in the center of Tokyo travel quite extended distances to work.
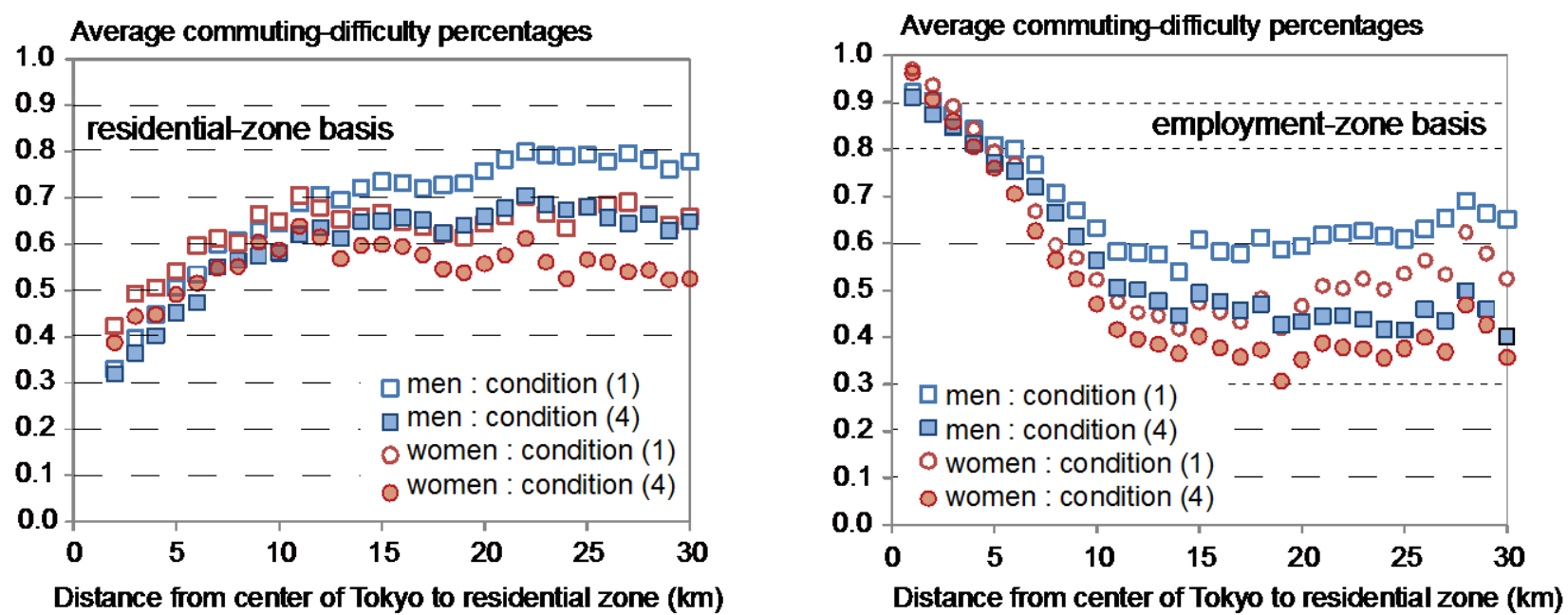

Figure 15. Average percentages of commuting difficulty for men versus women according to distance from the urban center of Tokyo.

In examining the employment-zone basis, no difference appeared owing to mode of travel between men and women working in the zone within $5 \mathrm{~km}$ of the center of Tokyo, but outside this zone, men again showed a higher percentage of difficulty in commuting. It may be stated that a larger percentage of the male population both work in the suburbs and also commute over extended distances.

The flattening of percentages of commuting difficulty for men and women working in locations $12 \mathrm{~km}$ from the center of Tokyo was common to both residential-zone-based and employmentzone-based calculations.

\subsection{Professional Differences in Percentages Having Difficulty in Commuting}

Percentages of commuting difficulty gauged by occupation on an employment-zone basis were compared under conditions (1) and (4); those travel modes of walking/cycling, and of walking/cycling/driving/busing, respectively. Beginning with spatial distributions (Figure 16), we note a higher percentage of commuting difficulty among personnel in administrative and managerial, professional and engineering, and clerical positions than for those in services (other) jobs; in many regions of central Tokyo, administrative and managerial, professional and engineering, or clerical categories registered difficulty of $80 \%$. Over against other occupations, administrators and managers in 
more employment zones reported an $80 \%$ difficulty in commuting, even well outside central Tokyo. This is surely because a relatively high number of persons in administrative and managerial positions reside in the suburbs and must, therefore, commute long distances.

Let us now turn to how percentages in commuting difficulty varied by distance from the employment zone to the center of Tokyo (Chiyoda 1-1-1, or the Imperial Palace) (Figure 17). Little variation was found with occupation, but services (other) jobs manifested a sharply decreasing percentage of commuting difficulty with distance from central Tokyo. This is because workers in services located in the suburbs have relatively short commutes. Administrators and managers claimed the highest percentage of difficulty in commuting under travel-mode Condition (1), which is limited to walking or cycling, when their workplaces were $10 \mathrm{~km}$ from central Tokyo, but showed little difference from workers in professional and engineering or clerical jobs under Condition (4), where travel was permitted by walking/cycling/driving/busing. Workers in administrative and managerial positions are relatively older than those in other job categories and suffer from lower mobility; these factors raise the percentage of commuter difficulty, unless it is possible for an employee to drive or take a bus.
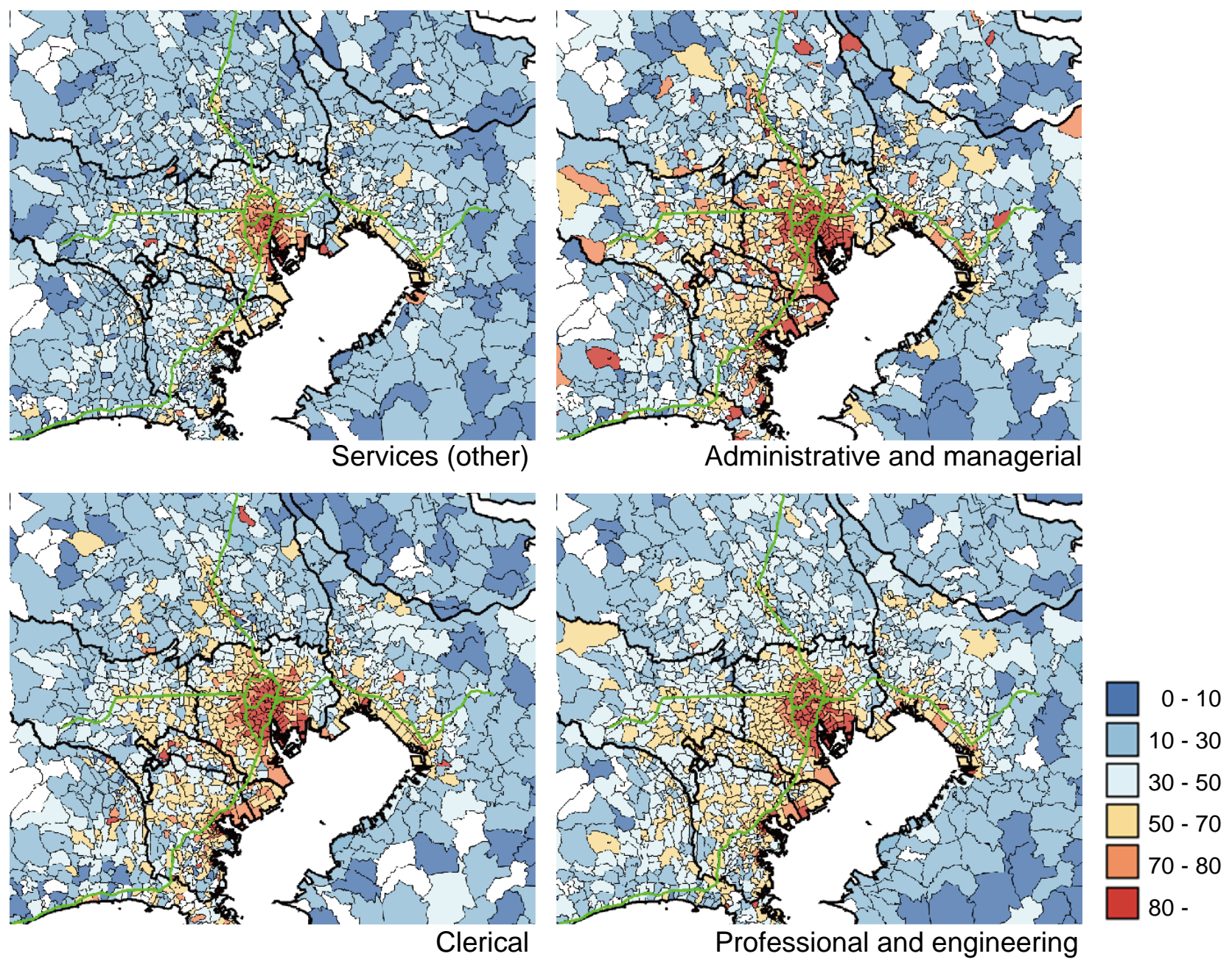

Figure 16. Spatial distribution of percentages of commuting difficulty yielded by four occupational categories on an employment-zone basis under travel-mode Condition (4). 

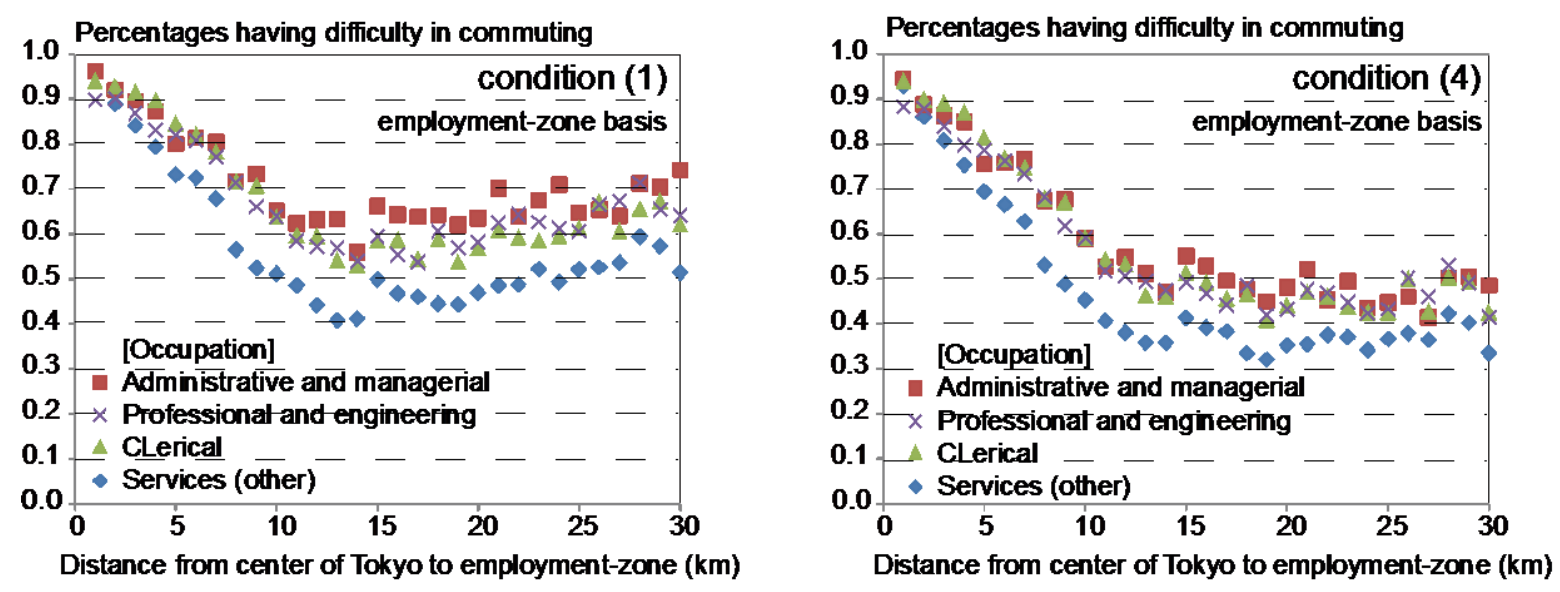

Figure 17. Percentages of commuting difficulty versus distance of employment zone from the center of Tokyo.

\section{Improvement in Difficulty of Commuting Following Restoration of Rail Infrastructure}

Our final investigation addressed travel-mode Condition (5), where it was assumed possible to walk, ride a bicycle, or take a train. It is notoriously difficult to anticipate which train lines are likely to be returned to full operation or in which order. Therefore, several combinations of restored operation were assumed and their resulting reductions in percentage of commuting difficulty were analyzed. In other words, the results were examined to explore the relative contributions made by restoration of service to different hypothetical combinations of lines. These four combinations ( $c f$. Figure 18) were Case (1) no restored train lines; Case (2) Yamanote line; Case (3) lines joining suburbs with central Tokyo; and Case (4) Yamanote line and lines joining suburbs with central Tokyo, namely a combination of Case (2) and Case (3).

Figure 18 plots spatial distribution of improvements in percentages of commuting difficulty following restoration of service in the following cases. For Case (2), on a residential-zone basis, once the Yamanote line was up and running, percentages of commuting difficulty in districts adjoining the line showed improvements of more than $30 \%$, but on an employment-zone basis, this was less than $10 \%$ in many other zones. On the other hand, for Case (3), significant improvement was found after radial lines from the suburbs were restored; on a residential-zone basis, these were particularly high (more than 30\%), and were concentrated east of Tokyo itself but in the west of Chiba Prefecture. However, we cannot expect great reductions in percentages of commuting difficulty from only the restoration of either the Yamanote line (Case (2)) or the radial lines from the suburbs (Case (3)) alone, as considered on an employment-zone basis for the center of Tokyo.

Next, as in Case (4), the benefits accruing from restoration of both the Yamanote line and the radial lines to the suburbs were examined (Figure 19). In Case (3), when only the radial lines were restored, high reductions in percentages of commuting difficulty were obtained only in locations adjacent to those lines. When the Yamanote line was combined with the radial suburban lines, the percentages of commuting difficulty greatly decreased, not only along the restored lines, but also in central Tokyo. The spatial distribution of improvement resulting from combined restoration of service appears not only adjacent to the Yamanote line itself; it likewise manifests a dramatically high improvement along the various radial lines. In other words, once the feeder lines to the center of Tokyo are restored, in addition 
to the Yamanote line, the ability of workers living in the suburbs to commute is vastly improved, and at the same time, the percentage of commuting difficulty among those employed in the center of Tokyo is also greatly ameliorated.

[ residential-zone basis ]

(2) Yamanote line

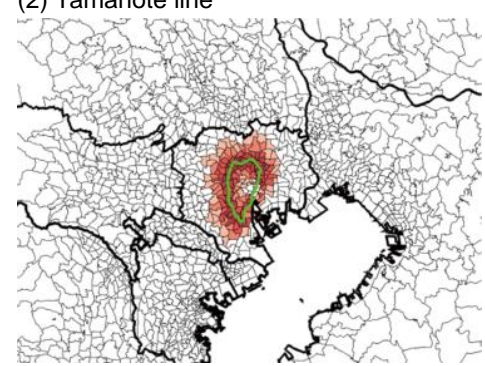

[ employment-zone basis ]

(2) Yamanote line

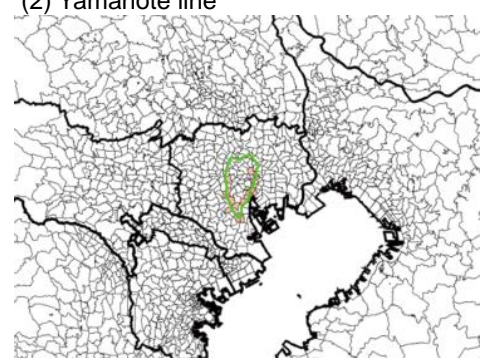

(3) lines joining suburbs with central Tokyo

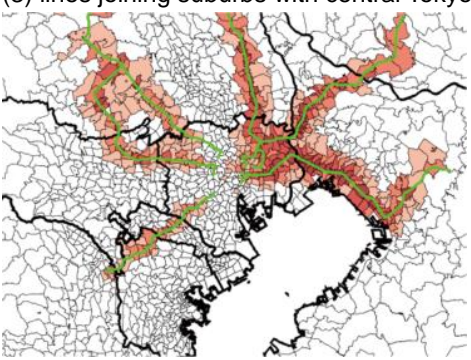

(3) lines joining suburbs with central Tokyo

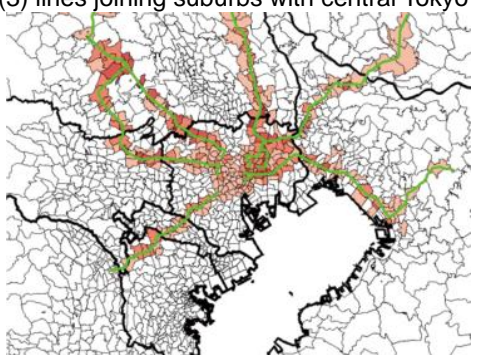

[ combinations of restored operation ]

Case (1) no restored train lines,

Case (2) Yamanote line

Case (3) lines joining suburbs with central Tokyo

Case (4) Yamanote line and lines joining suburbs with central Tokyo

(i.e., a combination of Cases (2) and (3))

Improvements in percentages of people with difficulty in commuting following restoration of service

$r_{i}^{b a}=\frac{R_{i}^{b}-R_{i}^{a}}{R_{i}^{1}} \times 100 \quad(\%)$

$r_{i}^{b a}:$ Improvements in percentages of people with difficulty in commuting in zone $i$ when available railways are changed from $b$ to case $a(\%)$

$R_{i}^{j}$ :Improvements in percentages of people with difficulty in commuting in zone $i$ when available railways are case $j(\%)$

Figure 18. Improvements in percentages of commuting difficulty based on a full recovery of the central Yamanote belt railway, plus lines linking outlying suburbs with central Tokyo.

[ residential-zone basis ]

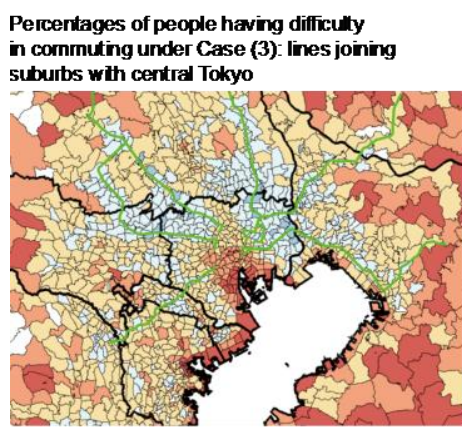

Improvernents in percentages of people having difficulty in cornmuting by combining restration of Yamanote line

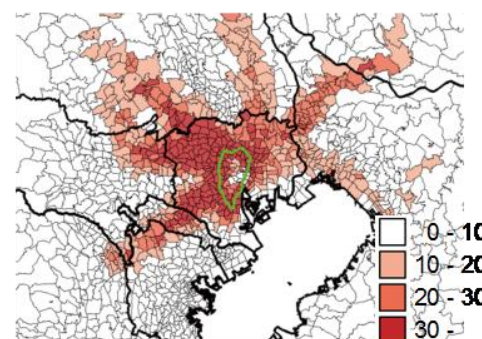

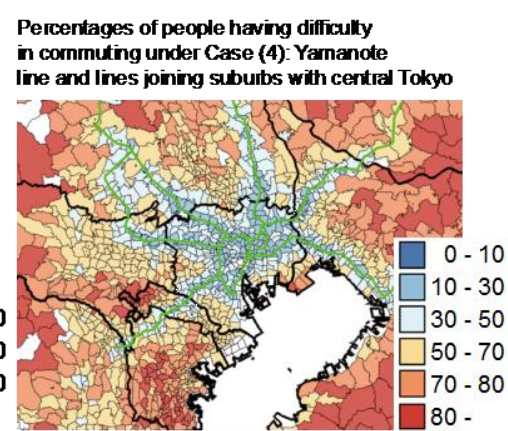

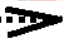

\section{[ employment-zone basis ]}

Percentages of people having difficulty in commuting under Case (3): lines joining suburbs with central Tokyo

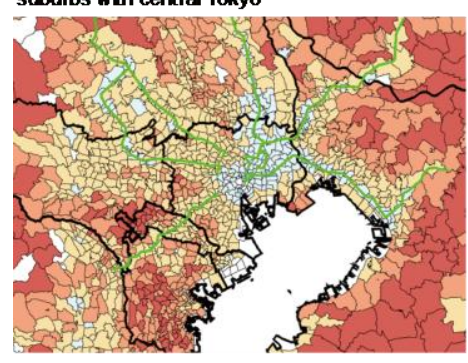

Improvernents in percentages of people
having difficulty in cornmuting by combining having difficulty in commuting
restration of Yamanote line

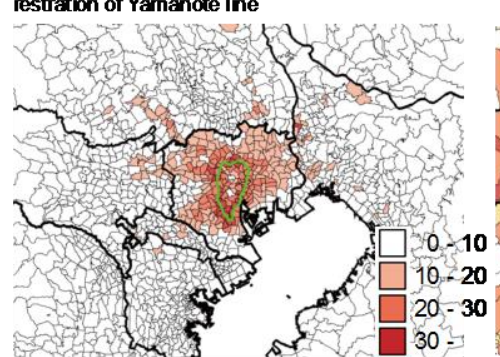

Percentages of people having difficulty in commuting under Case (4): Yamanote line and lines joining suburbs with central Tokyo

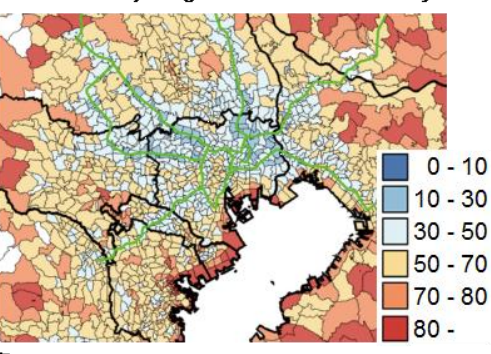

Figure 19. Improvements in percentages of commuting difficulty following restoration of transport services by residential and employment zones. 


\section{Summary and Conclusions}

This article presents a survey of commuting behavior after a hypothetical large seismic event in Greater Tokyo and for the purpose of constructing a model in order to estimate the general ability of individuals to commute to work in the period immediately following such an earthquake. The survey data were used to construct a model of commuting intention, which describes respondents' intent to continue commuting to work, while accounting for both respondent attributes and commuting times under ordinary conditions; and a mobility model, which characterizes respondents' physical mobility in terms of either walking or riding a bicycle. Next, extant commuting data for workers were extracted from an extensive person-trip database in order to estimate the actual likelihood of individuals to continue to commute to their jobs based on these two models. Various percentages of commuting difficulty are defined in order to quantify the obstacles that people in different regions of this vast conurbation may face in continuing to reach the workplace; in addition, the strategic locale of residence and employment as well as the attributes of their respective working populations by zone are discussed and wherever possible submitted to analysis.

Percentages of commuting difficulty vary greatly in accordance with gender, occupation, and regional characteristics. Therefore, the debate over any post-disaster continuity of regional activity should be based not only on the establishment of local BCPs and DCPs, but also on the attributes of those various population segments experiencing difficulty in commuting. Geographically speaking, from the viewpoint of residential zones, extremely high percentages of commuting difficulty were observed in the northern part of Kawasaki, which is Japan's eighth largest city, and the western (urban) part of Chiba Prefecture. While these regions possess excellent access to the commercial centers of Tokyo, Yokohama, Japan's second largest city, and other regional agglomerations, their populations are also highly raildependent. Many would face impediments to workplace access, even if automobiles and buses were running in normal fashion. From the viewpoint of employment zones, a large fraction of those who work in the center of Tokyo and who commute over long distances are similarly rail-dependent. A very large number would encounter serious difficulties if unable to make use of rail service, regardless of whether cars and buses were able to circulate.

On the basis of our quantified results and after consideration of improvements in percentages of workers having difficulty in commuting following full restoration of the regional rail infrastructure, it is clear that the percentages of commuting difficulty of those who work in central Tokyo will be alleviated only after the restoration of railway service linking the center with the suburbs, where many workers live, and of belt rail services, of which the central Yamanote line is the oldest, most traveled, and most central. As is already well understood, such restorations of service will also impact the ability of workers to commute within and between the inner and outer suburbs generally.

It is essential to expedite repairs to railways to ensure the early recovery and continuation of regional activities in central Tokyo. As shown by the models discussed here, any proposed plan for the restoration of rail service must scrutinize the benefits of all the various possible combinations of promptly restored service in terms of percentages of the working population experiencing post-quake commuting difficulty, so that such repairs are rendered as efficient and expeditious as possible.

The respondents were asked to have three conditions in mind while answering to the questionnaire: (1) post-earthquake conditions, (2) reception/non-reception of instructions to return to work, and 
(3) available means of transportation. The results obtained in this research were obviously dependent on the conditions that respondents had in mind. Further research is, therefore, needed for discussing the effects of the conditions to be assumed.

\section{Acknowledgments}

The author would like to extend special thanks to David B. Stewart (Tokyo Institute of Technology) for proofreading and editorial comments; and also to Saori Tamano for her computer-based numerical calculations. An earlier version of this manuscript was critiqued by three anonymous reviewers, whose insightful comments greatly helped to improve the paper.

\section{Disclaimer}

The present study is based on data supplied by the Tokyo Metropolitan Area Transportation Planning Council. Any interpretation of said data as well as the conclusions stated here are those of the researchers and in no way represent views of the Council.

\section{Conflict of Interest}

The authors declare no conflict of interest.

\section{References}

1. Schmitt, R.R. A brief overview of the Northridge earthquake and its transportation impacts. $J$. Transp. Stat. 1998, 1, v-vi.

2. Giuliano, G.; Golob, J. Impacts of the Northridge earthquake on transit and highway use. J. Transp. Stat. 1998, 1, 1-20.

3. Willson, R. Impacts and responses: Goods movement after the Northridge earthquake. J. Transp. Stat. 1998, 1, 37-48.

4. Boarnet, M. Business losses, transportation damage, and the Northridge earthquake. J. Transp. Stat. 1998, 1, 49-73.

5. Nishikawa, S.; Beniya, S.; Nagamatsu, S.; Nonaka, M. Business participation in district based disaster preparedness activities, a new move towards district-wide business continuity planning in commercial zones. In Proceedings of the 2007 Annual Conference of the Institute of Social Safety Science, Shizuoka, Japan, 10 November 2007.

6. Osaragi, T. Modeling a spatiotemporal distribution of stranded people returning home on foot in the aftermath of a large-scale earthquake. Nat. Hazards 2012, 68, 1385-1398.

7. Kadam, A. Personal business continuity planning. Inf. Secur. J. A Glob. Perspect. 2010, 19, 4-10.

8. Nakabayashi, I. Development of estimation method on obstructed homeward commuters after earthquake disaster. Compr. Urban Stud. 1992, 47, 35-75.

9. Sekizawa, A. Study on emergency summons of staffs in an earthquake disaster situation. In Summaries of Technical Papers of Annual Meeting. Architectural Institute of Japan: Nagoya, Japan, 1994; pp. 609-610. 
10. Takahashi, M.; Yashiro, H.; Fukushima S. Development of access evaluation system for emergency action. In Proceedings of the 2000 Annual Conference of the Institute of Social Safety Science, Shizuoka, Japan, 17 November 2000.

11. Iida, Y.; Kurachi, F.; Shimada, H. Personal business continuity planning. IATSS Res. 2000, 24, 6-17.

12. Osaragi, T.; Tamano, S. Difficulty in commuting in the aftermath of a devastating earthquake. $J$. Archit. Plan. Eng. 2013, 78, 107-114. (In Japanese)

13. Nakamura, M. Estimated damage caused by future earthquakes occurring beneath Tokyo: From damage estimation research revised in 2006. J. Geogr. (Chigaku Zasshi) 2007, 116, 504-510.

14. Rosenblatt, F. The Perceptron: A probabilistic model for information storage and organization in the Brain. Psychol. Rev. 1958, 65, 386-408.

15. Cybenko, G. Approximation by superpositions of a sigmoidal function. Math. Control Signals Syst. 1989, 2, 303-314.

16. Rosenblatt, F. Principles of Neurodynamics: Perceptrons and the Theory of Brain Mechanisms; University of Michigan: Washington, DC, USA, 1962.

17. Minsky M.; Papert S.A. Perceptrons: An Introduction to Computational Geometry; The MIT Press: Cambridge, MA, USA, 1969.

18. Ministry of Education, Culture, Sports, Science and Technology (MEXT). Statistical Abstract 2006-Physical Education and Sports (Motor Fitness of Students [Male/Female]), 3rd ed.; Tokyo Metropolitan Government: Tokyo, Japan, 2006.

19. Osaragi, T. Spatiotemporal distribution of automobile users: Estimation method and applications to disaster mitigation planning. In Proceedings of the 12th International Conference on Information Systems for Crisis Response and Management, Kristiansand, Norway, 24-27 May 2015.

20. Road Traffic Census by the Ministry of Land, Infrastructure, Transport and Tourism. Available online: http://www.mlit.go.jp/road/road_e/statistics.html (accessed on 18 March 2012).

(C) 2015 by the authors; licensee MDPI, Basel, Switzerland. This article is an open access article distributed under the terms and conditions of the Creative Commons Attribution license (http://creativecommons.org/licenses/by/4.0/). 